\title{
Prior treatment status: impact on the efficacy and safety of teriflunomide in multiple sclerosis
}

\author{
Giancarlo Comi ${ }^{1 *}$, Mark S. Freedman², José E. Meca-Lallana ${ }^{3,4}$, Patrick Vermersch ${ }^{5}$, Byoung Joon Kim \\ Alexander Parajeles ${ }^{7}$, Keith R. Edwards ${ }^{8}$, Ralf Gold ${ }^{9}$, Houari Korideck ${ }^{10,11}$, Jeffrey Chavin ${ }^{10}$, \\ Elizabeth M. Poole ${ }^{10,12}$ and Patricia K. Coyle ${ }^{13}$
}

\begin{abstract}
Background: In this pooled, post hoc analysis of a phase 2 trial and the phase 3 TEMSO, TOWER, and TENERE clinical trials, long-term efficacy and safety of teriflunomide were assessed in subgroups of patients with relapsing multiple sclerosis (MS) defined by prior treatment status.

Methods: Patients were classified according to their prior treatment status in the core and core plus extension periods. In the core period, patients were grouped according to treatment status at the start of the study: treatment naive (no prior disease-modifying therapy [DMT] or DMT $>2$ years prior to randomization), previously treated with another DMT (DMT $>6$ to $\leq 24$ months prior to randomization), and recently treated with another DMT (DMT $\leq 6$ months prior to randomization). In the core plus extension period, patients were re-baselined to the time of starting teriflunomide $14 \mathrm{mg}$ and grouped according to prior treatment status at that time point. Efficacy endpoints included annualized relapse rate (ARR), probability of confirmed disability worsening (CDW) over 12 weeks, and Expanded Disability Status Scale (EDSS) score. The incidence of adverse events was also assessed.

Results: Most frequently received prior DMTs at baseline were glatiramer acetate and interferon beta-1a across treatment groups. Teriflunomide $14 \mathrm{mg}$ significantly reduced ARR versus placebo in the core period, regardless of prior treatment status. In the core and extension periods, adjusted ARRs were low (0.193-0.284) in patients treated with teriflunomide $14 \mathrm{mg}$ across all subgroups. Probability of CDW by Year 4 was similar across subgroups; by Year 5, the percentage of patients with 12-week CDW was similar in treatment-naive patients and patients recently treated with another DMT (33.9 and 33.7\%, respectively). EDSS scores were stable over time in all prior-treatment subgroups. There were no new or unexpected safety signals. Limitations include selective bias due to patient attrition, variability in subgroup size, and lack of magnetic resonance imaging outcomes.
\end{abstract}

Conclusions: The efficacy and safety of teriflunomide $14 \mathrm{mg}$ was similar in all patients with relapsing MS, regardless of prior treatment history.

Trial registration: Phase 2 trial core: NCT01487096; Phase 2 trial extension: NCT00228163; TEMSO core: NCT00134563; TEMSO extension: NCT00803049; TOWER: NCT00751881; TENERE: NCT00883337.

Keywords: Disease-modifying therapy, Multiple sclerosis, Relapse rate, Teriflunomide, Treatment history

\footnotetext{
* Correspondence: comi.giancarlo@hsr.it

'Ospedale San Raffaele, Via Olgettina 58, 20132 Milan, Italy

Full list of author information is available at the end of the article
}

(c) The Author(s). 2020 Open Access This article is licensed under a Creative Commons Attribution 4.0 International License, which permits use, sharing, adaptation, distribution and reproduction in any medium or format, as long as you give appropriate credit to the original author(s) and the source, provide a link to the Creative Commons licence, and indicate if changes were made. The images or other third party material in this article are included in the article's Creative Commons licence, unless indicated otherwise in a credit line to the material. If material is not included in the article's Creative Commons licence and your intended use is not permitted by statutory regulation or exceeds the permitted use, you will need to obtain permission directly from the copyright holder. To view a copy of this licence, visit http://creativecommons.org/licenses/by/4.0/ The Creative Commons Public Domain Dedication waiver (http://creativecommons.org/publicdomain/zero/1.0/) applies to the data made available in this article, unless otherwise stated in a credit line to the data. 


\section{Background}

In the 1990s and early 2000s, interferon beta (IFNB) and glatiramer acetate (GA) were the only disease-modifying therapies (DMTs) available for patients with relapsing forms of multiple sclerosis (RMS) [1]. In the past decade, additional DMTs with varying mechanisms of action have been approved [2]. Injectable DMTs continue to be used as first-line therapies for their efficacy and safety profiles [1, 3]; however, breakthrough disease activity, suboptimal tolerability, and patient nonadherence may necessitate a switch to another therapy. Few data are available on treatment sequencing and whether prior treatment experience impacts efficacy and safety of the second DMT after a switch.

Teriflunomide is a once-daily oral immunomodulator approved for the treatment of RMS or relapsingremitting MS, depending on the local label, in more than 80 countries, including the United States [4] and countries of the European Union [5]. As of 2019, more than 100,000 patients were being treated with teriflunomide, with a total real-world exposure of approximately 285,800 patient-years. The efficacy and safety of teriflunomide have been established in a phase 2 trial (core: NCT01487096; extension: NCT00228163) [6], and the phase 3 TEMSO (core: NCT00134563; extension: NCT00803049) [7], TOWER (NCT00751881) [8], and TENERE (NCT00883337) [9] clinical trials. In the phase 2 study, TEMSO, and TOWER, teriflunomide $14 \mathrm{mg}$ significantly reduced annualized relapse rate (ARR) and confirmed disability worsening (CDW) compared with placebo [6-8]. In TENERE, adjusted ARRs with teriflunomide $14 \mathrm{mg}$ were the same as those for IFNB-1a [9].

In a previous analysis on the effect of number of prior DMTs on teriflunomide efficacy in the TEMSO and TOWER core studies, patients treated with teriflunomide $14 \mathrm{mg}$ had reduced ARR and risk of disability worsening, regardless of whether they received a prior DMT [10]. The aim of the present analysis was to expand on these findings by evaluating efficacy and safety of teriflunomide in the long-term, in subgroups of patients defined by prior treatment status and recency.

\section{Methods}

\section{Patients and study design}

In this post hoc analysis, data were pooled from the phase 2 and phase 3 TEMSO, TOWER, and TENERE clinical trials and their extension studies (trial registrations: phase 2 trial core, NCT01487096; phase 2 trial extension, NCT00228163; TEMSO core, NCT00134563; TEMSO extension, NCT00803049; TOWER, NCT00751881; TENE RE, NCT00883337). Complete study designs for these trials have been reported previously [6-9] and are summarized briefly below. The randomized studies contributing to this analysis adhered to CONSORT reporting guidelines.

Patients were eligible to participate in the clinical trials if they had RMS, were aged $\geq 18$ years (upper age limit: 55 years for TEMSO and TOWER, 65 years for the phase 2 study, no limit for TENERE), and had an Expanded Disability Status Scale (EDSS) score $\leq 5.5$ (TEMSO/ TOWER/TENERE) or $\leq 6$ (phase 2 study). Further eligibility criteria were 1 clinical relapse in the preceding year (phase 2 study) [6], $\geq 1$ relapses in the previous 1 year, or $\geq 2$ relapses in the previous 2 years (TOWER) [8]; or $\geq 2$ clinical relapses in the previous 2 years or 1 relapse during the preceding year, without relapses in the 60 days before randomization (TEMSO) [7]. In TENERE, patients could not have had a clinical relapse in the 30 days prior to randomization [9].

In the phase 2, TEMSO, and TOWER core studies, patients were randomized 1:1:1 to receive placebo, teriflunomide $7 \mathrm{mg}$, or teriflunomide $14 \mathrm{mg}$ for up to 36 weeks, 108 weeks, or $\geq 48$ weeks, respectively. Patients treated with teriflunomide continued their original dose (phase 2/TEMSO) or received teriflunomide $14 \mathrm{mg}$ regardless of original dose (TOWER). Placebo-treated patients were reassigned to teriflunomide $7 \mathrm{mg}$ or $14 \mathrm{mg}$ (phase 2/TEMSO) or teriflunomide $14 \mathrm{mg}$ (TOWER). In the TENERE core study, patients were randomized 1:1:1 to receive teriflunomide $7 \mathrm{mg}$, teriflunomide $14 \mathrm{mg}$, or subcutaneous IFNB-1a $44 \mu \mathrm{g}$ for $\geq 48$ weeks; all patients received teriflunomide $14 \mathrm{mg}$ in the extension.

For each study, patients who received previous DMT were eligible to participate, with the following exceptions: in the phase 2 and TENERE studies, patients were not eligible to participate if they had received prior

Table 1 Definitions of prior MS treatment groups (core and extension analysis)

\begin{tabular}{lll}
\hline Group & Definition & $\begin{array}{l}\text { Maximum time } \\
\text { point available }\end{array}$ \\
\hline Treatment naive & Patients with no prior DMT or DMT > 2 years prior to randomization \\
Previously treated with another DMT & $\begin{array}{l}\text { Patients whose most recent prior DMT was discontinued }>6 \text { months } \\
\text { to } 2 \text { years prior to randomization }\end{array}$ \\
Recently treated with another DMT & $\begin{array}{l}\text { Patients whose most recent prior DMT was discontinued within } 6 \\
\text { months prior to randomization (excluded patients who recently } \\
\text { received teriflunomide } 7 \mathrm{mg})\end{array}$ \\
\hline
\end{tabular}


treatment with IFNB within 4 or 3 months prior to randomization, respectively, and in all trials, patients could not enroll if they had received prior or concomitant treatment with cladribine, mitoxantrone, or other immunosuppressants. Data were not available on reason for stopping or switching from previous DMT.

\section{Study endpoints}

Efficacy endpoints included ARR, probability of disability worsening confirmed over 12 weeks, and EDSS score. Cumulative duration of teriflunomide exposure and occurrence of adverse events (AEs) were also assessed.

In the phase 2 study, a relapse was defined as the appearance of a new symptom or worsening of a previous symptom due to MS, lasting $48 \mathrm{~h}$ in the absence of fever, and preceded by a period of stability of at least 30 days [6]. In the phase 3 trials, confirmed relapses were defined as new or worsening symptoms lasting $\geq 24 \mathrm{~h}$ without fever; relapses required an increase of 1 point in each of 2 EDSS functional system scores, or 2 points in 1 EDSS functional system score (excluding bowel and bladder function and cerebral function), or an increase of $\geq 0.5$ points in EDSS score from the previous clinically stable assessment [7-9]. CDW was defined as an increase from baseline of $\geq 1.0$ point in EDSS score (or $\geq 0.5$ points for patients with a baseline EDSS score $\geq 5.5$ ) confirmed over $\geq 12$ weeks.

In the analysis of core study data, patients were grouped according to prior MS DMT status at core study baseline: treatment naive (including those treated $>2$ years prior to randomization), previously treated with another DMT (> 6 months to $\leq 24$ months prior to randomization), and recently treated with another DMT ( $\leq 6$ months prior to randomization). The recently treated group included patients who had received IFNB-1a in the core TENERE study who entered the extension and were treated with teriflunomide $14 \mathrm{mg}$; their first 108 weeks on

Table 2 Baseline demographics and disease characteristics (core period; safety population)

\begin{tabular}{|c|c|c|c|c|c|c|c|c|}
\hline & \multicolumn{2}{|c|}{$\begin{array}{l}\text { Treatment naive } \\
(n=1244)\end{array}$} & \multicolumn{2}{|c|}{$\begin{array}{l}\text { Previously treated with } \\
\text { another DMT } \\
(n=270)\end{array}$} & \multicolumn{2}{|c|}{$\begin{array}{l}\text { Recently treated with } \\
\text { another DMT } \\
(n=247)\end{array}$} & \multicolumn{2}{|c|}{$\begin{array}{l}\text { Overall population } \\
(N=1702)^{\mathrm{a}}\end{array}$} \\
\hline & $\begin{array}{l}\text { Placebo } \\
(n=586)\end{array}$ & $\begin{array}{l}\text { Teriflunomide } \\
14 \mathrm{mg} \\
(n=658)\end{array}$ & $\begin{array}{l}\text { Placebo } \\
(n=131)\end{array}$ & $\begin{array}{l}\text { Teriflunomide } \\
14 \mathrm{mg} \\
(n=139)\end{array}$ & $\begin{array}{l}\text { Placebo } \\
(n=89)\end{array}$ & $\begin{array}{l}\text { Teriflunomide } \\
14 \mathrm{mg} \\
(n=158)\end{array}$ & $\begin{array}{l}\text { Placebo } \\
(N=806)\end{array}$ & $\begin{array}{l}\text { Teriflunomide } 14 \\
\mathrm{mg}(N=896)^{\mathrm{a}}\end{array}$ \\
\hline Age, mean (SD) years & $38.8(9.0)$ & $37.9(9.2)$ & $37.5(8.6)$ & $37.9(8.4)$ & $\begin{array}{l}36.4 \\
(9.5)\end{array}$ & $39.0(9.6)$ & $38.3(9.0)$ & $38.0(9.1)$ \\
\hline Female gender, $n(\%)$ & $\begin{array}{l}414 \\
(70.6)\end{array}$ & $458(69.6)$ & $\begin{array}{l}105 \\
(80.2)\end{array}$ & $103(74.1)$ & $65(73.0)$ & $114(72.2)$ & $584(72.5)$ & $634(70.8)$ \\
\hline White, $n(\%)$ & $\begin{array}{l}518 \\
(88.5)^{b}\end{array}$ & $595(90.4)$ & $\begin{array}{l}124 \\
(94.7)\end{array}$ & $131(94.9)^{c}$ & $84(94.4)$ & $154(97.5)$ & $\begin{array}{l}726 \\
(90.2)^{d}\end{array}$ & $821(91.7)^{\mathrm{e}}$ \\
\hline $\begin{array}{l}\text { Time since diagnosis of MS, } \\
\text { mean (SD) years }\end{array}$ & $\begin{array}{l}4.42 \\
(5.73)\end{array}$ & $4.40(5.55)^{f}$ & $\begin{array}{l}6.83 \\
(4.92)\end{array}$ & $8.00(5.55)$ & $\begin{array}{l}5.85 \\
(5.26)\end{array}$ & $6.18(6.04)$ & $\begin{array}{l}4.97 \\
(5.62)\end{array}$ & $5.24(5.85)^{\mathrm{e}}$ \\
\hline $\begin{array}{l}\text { Time since first symptoms of } \\
\mathrm{MS} \text {, mean (SD) years }\end{array}$ & $\begin{array}{l}7.79 \\
(7.28)\end{array}$ & $7.49(6.74)^{f}$ & $\begin{array}{l}9.26 \\
(5.63)\end{array}$ & $10.90(6.87)$ & $\begin{array}{l}8.79 \\
(7.02)\end{array}$ & $9.39(7.19)$ & $\begin{array}{l}8.14 \\
(7.02)\end{array}$ & $8.26(6.91)^{\mathrm{e}}$ \\
\hline $\begin{array}{l}\text { Number of relapses within } \\
\text { past year, mean (SD) }\end{array}$ & $\begin{array}{l}1.40 \\
(0.71)^{9}\end{array}$ & $1.37(0.69)^{h}$ & $\begin{array}{l}1.42 \\
(0.87)^{\mathrm{i}}\end{array}$ & $1.36(0.81)^{j}$ & $\begin{array}{l}1.49 \\
(0.81)^{k}\end{array}$ & $0.90(0.88)^{\prime}$ & $\begin{array}{l}1.42 \\
(0.75)^{\mathrm{m}}\end{array}$ & $1.37(0.71)^{n}$ \\
\hline \multicolumn{9}{|l|}{ Baseline EDSS score } \\
\hline Mean (SD) & $\begin{array}{l}2.61 \\
(1.37)\end{array}$ & $2.57(1.33)$ & $\begin{array}{l}2.97 \\
(1.32)\end{array}$ & $2.79(1.37)$ & $\begin{array}{l}2.58 \\
(1.37)\end{array}$ & $2.49(1.38)$ & $\begin{array}{l}2.67 \\
(1.37)\end{array}$ & $2.64(1.34)$ \\
\hline Median (min, max) & $\begin{array}{l}2.50(0.0, \\
6.0)\end{array}$ & $2.50(0.0,6.5)$ & $\begin{array}{l}3.00(0.0, \\
6.0)\end{array}$ & $2.50(0.0,6.0)$ & $\begin{array}{l}2.50 \\
(0.0,5.5)\end{array}$ & $2.00(0.0,6.5)$ & $\begin{array}{l}2.50(0.0 \\
6.0)\end{array}$ & $2.50(0.0,6.5)$ \\
\hline \multicolumn{9}{|l|}{ Last prior DMT, ${ }^{\mathrm{O} p}$ n (\%) } \\
\hline Fingolimod & 0 & $1(4.5)$ & $1(0.8)$ & $3(2.2)$ & 0 & 0 & $1(0.4)$ & $4(1.5)$ \\
\hline GA & $6(27.3)$ & $4(18.2)$ & $42(32.1)$ & $51(36.7)$ & $33(37.1)$ & $27(17.1)$ & $81(33.5)$ & $82(31.5)$ \\
\hline $\mathrm{IFNB}^{\mathrm{q}}$ & 0 & 0 & $3(2.3)$ & 0 & $2(2.2)$ & $2(1.3)$ & $5(2.1)$ & $2(0.8)$ \\
\hline IFNB-1a & $11(50.0)$ & $9(40.9)$ & $57(43.5)$ & 55 (39.6) & $36(40.4)$ & $110(69.6)$ & $104(43.0)$ & $115(44.2)$ \\
\hline IFNB-1b & $5(22.7)$ & $8(36.4)$ & 27 (20.6) & $27(19.4)$ & $18(20.2)$ & $19(12.0)$ & $50(20.7)$ & $54(20.8)$ \\
\hline Natalizumab & 0 & 0 & $1(0.8)$ & $3(2.2)$ & 0 & 0 & $1(0.4)$ & $3(1.2)$ \\
\hline
\end{tabular}

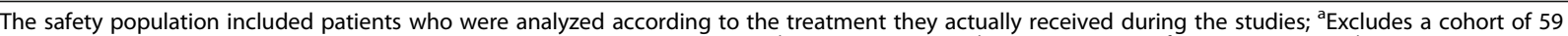
patients who switched from IFNB-1a to teriflunomide $14 \mathrm{mg}$ (TENERE study); ${ }^{\mathrm{b}} n=585 ;{ }^{\mathrm{c}} n=138 ;{ }^{\mathrm{d}} n=805 ;{ }^{\mathrm{e}} n=895 ;{ }^{\mathrm{f}} n=657 ;{ }^{\mathrm{g}} n=521 ;{ }^{\mathrm{h}} n=598 ;{ }^{\mathrm{i}} n=112 ;{ }^{\mathrm{j}} n=119 ;$ ${ }^{k} n=86 ;{ }^{1} n=151 ;{ }^{m} n=719 ;{ }^{n} n=809 ;{ }^{\circ}$ Treatment-naive subgroup (no prior DMT in the 2 years prior to randomization): placebo, $n=22 ;$ TFL 14 mg, $n=22 ;{ }^{\mathrm{P}}$ Last prior DMT data were based on a total of 242 placebo-treated patients and 260 teriflunomide 14 mg-treated patients for the overall population; ${ }^{9}$ IFNB formulation not specified. DMT disease-modifying therapy, EDSS Expanded Disability Status Scale, GA glatiramer acetate, IFNB interferon beta, max maximum, min minimum, MS minimum sclerosis, SD standard deviation, TFL teriflunomide 
teriflunomide in the extension study were included in the teriflunomide $14 \mathrm{mg}$ core study data analysis.

In the analyses of the core plus extension period, baseline was considered the time that patients started teriflunomide $14 \mathrm{mg}$. Patients were grouped according to prior treatment status: treatment naive, previously treated with another DMT, and recently treated with another DMT (Table 1).

\section{Statistical analysis}

Patients who received teriflunomide $7 \mathrm{mg}$ during the core period were not considered in the analysis. Two patient populations were included: the modified intention-to-treat population for efficacy outcomes, in which patients who received one or more study doses were analyzed according to the treatment group to which they were randomized, and the safety population, in which patients were analyzed according to the treatment they actually received.

Adjusted ARRs were compared between patients receiving placebo or teriflunomide according to the subgroups of prior treatment status and were derived using a Poisson regression model adjusted for baseline EDSS stratum (< 3.5 vs $\geq 3.5$ ), age, gender, region, time since first diagnosis of MS, number of relapses in the year prior, and study. The response variable was the total number of confirmed relapses with an onset between randomization date and last dose date. Log-transformed study duration was included as an offset variable. Probability of 12-week CDW was assessed using Kaplan-Meier estimates.

\section{Results}

Baseline demographics and disease characteristics

Of patients treated with placebo or teriflunomide $14 \mathrm{mg}$ in the core period, 1244 were treatment naive, 270 were previously treated with another DMT, and 247 were recently treated with another DMT (Table 2). Most baseline demographics and disease characteristics were similar across subgroups, except for time since diagnosis of MS, time since first MS symptoms, and mean EDSS score, which were numerically higher in previously treated patients compared with the other subgroups (Table 2). Across all subgroups, most patients had received either GA (17.1-37.1\%) or IFNB-1a (39.6-69.6\%) as their most recent prior DMT.

In the safety population from the pooled core and extension studies, there were 1339 patients exposed to teriflunomide $14 \mathrm{mg}$, of whom 1018 were treatment naive (mean [standard deviation] exposure: 196.1 [148.3] weeks), 163 were previously treated (187.4 [161.4] weeks), and 158 were recently treated (160.7 [115.0] weeks) (Table 3). Patient

Table 3 Baseline characteristics at start of teriflunomide $14 \mathrm{mg}$ (core and extension period; safety population)

\begin{tabular}{|c|c|c|c|c|}
\hline & $\begin{array}{l}\text { Treatment naive } \\
(n=1018)\end{array}$ & $\begin{array}{l}\text { Previously treated with another } \\
\text { DMT }(n=163)\end{array}$ & $\begin{array}{l}\text { Recently treated with another } \\
\text { DMT }(n=158)\end{array}$ & $\begin{array}{l}\text { Overall Population } \\
(N=1696)^{\mathrm{a}}\end{array}$ \\
\hline Age, mean (SD) years & $38.64(9.06)$ & $37.82(8.24)$ & $38.97(9.62)$ & $38.68(9.12)$ \\
\hline Female gender, $n(\%)$ & $718(70.5)$ & $125(76.7)$ & $114(72.2)$ & $1211(71.4)$ \\
\hline White, $n(\%)$ & $918(90.3)^{b}$ & $154(95.1)^{c}$ & $154(97.5)$ & $1536(90.7)^{d}$ \\
\hline $\begin{array}{l}\text { Time since diagnosis of } \mathrm{MS} \text {, mean } \\
\text { (SD) years }\end{array}$ & $5.06(5.44)^{b}$ & $7.95(5.38)$ & $6.18(6.04)$ & $5.80(5.60)^{\mathrm{e}}$ \\
\hline $\begin{array}{l}\text { Time since first symptoms of MS, } \\
\text { mean (SD) years }\end{array}$ & $8.20(6.71)^{b}$ & $10.72(6.69)$ & $9.39(7.19)$ & $8.90(6.87)^{\mathrm{e}}$ \\
\hline $\begin{array}{l}\text { Number of relapses within past year, } \\
\text { mean (SD) }\end{array}$ & $1.00(0.82)^{f}$ & $1.22(0.85)^{\mathrm{g}}$ & $0.90(0.88)^{h}$ & $0.87(0.84)^{i}$ \\
\hline \multicolumn{5}{|l|}{ Baseline EDSS score } \\
\hline Mean (SD) & $2.59(1.43)$ & $2.74(1.40)$ & 2.49 (1.38) & $2.58(1.43)$ \\
\hline Median (min, max) & $2.50(0.0,8.0)$ & $2.50(0.0,6.5)$ & $2.00(0.0,6.5)$ & $2.50(0.0,8.0)$ \\
\hline \multicolumn{5}{|l|}{ Last prior DMT, $n(\%)$} \\
\hline Fingolimod & $2(1.8)$ & $3(1.8)$ & 0 & $5(0.6)$ \\
\hline GA & $36(33.0)$ & $58(35.6)$ & $27(17.1)$ & $121(15.4)$ \\
\hline $\mathrm{IFNB}^{\mid}$ & $1(0.9)$ & 0 & $2(1.3)$ & $3(0.4)$ \\
\hline IFNB-1a & $39(35.8)$ & $68(41.7)$ & $110(69.6)$ & $217(27.6)$ \\
\hline IFNB-1b & $31(28.4)$ & $31(19.0)$ & $19(12.0)$ & $81(10.3)$ \\
\hline Natalizumab & 0 & $3(1.8)$ & 0 & $3(0.4)$ \\
\hline Teriflunomide $7 \mathrm{mg}$ & 0 & 0 & 0 & $357(45.4)$ \\
\hline
\end{tabular}

Includes an additional cohort of 357 patients from the TOWER and TENERE studies who switched from teriflunomide $7 \mathrm{mg}$ to $14 \mathrm{mg}$ in the extension period; ${ }^{\mathrm{b}} \mathrm{n}=$ $1017 ;{ }^{c} n=162 ;{ }^{d} n=1694 ;{ }^{~} n=1695 ;{ }^{f} n=958 ;{ }^{g} n=143 ;{ }^{h} n=151 ;{ }^{i} n=1609 ;{ }^{j}$ Data reported in the treatment-naive subgroup include patients with DMT use $>2$ years prior to receiving teriflunomide $14 \mathrm{mg}(n=109)$; ${ }^{k}$ Last prior DMT data were based on a total of 787 patients for the overall population; IFNB formulation not specified; DMT disease-modifying therapy, EDSS Expanded Disability Status Scale, GA glatiramer acetate, IFNB interferon beta, max maximum, min minimum, MS multiple sclerosis, SD standard deviation 
baseline characteristics were similar across the subgroups at the time of starting teriflunomide $14 \mathrm{mg}$, except previously treated patients had numerically higher mean time since MS diagnosis, time since first symptoms of MS, number of relapses within the past year, and mean EDSS score compared with the other subgroups.

\section{Efficacy}

In the core period, overall adjusted ARR reduction for teriflunomide $14 \mathrm{mg}$ versus placebo was $34 \%(p<$ $0.0001)$ in treatment-naive patients, $34 \%(p=0.0073)$ in previously treated patients, and $41 \%(p=0.0042)$ in recently treated patients (Fig. 1).

In the core and extension period, overall adjusted ARRs (95\% confidence interval [CI]) for teriflunomide $14 \mathrm{mg}$ were $0.193(0.165-0.226)$ in treatment-naive patients, $0.284(0.216-0.372)$ in previously treated patients, and $0.272(0.207-0.357)$ in recently treated patients (Fig. 2).

The percentage of patients with 12-week CDW (95\% CI) was $52.7 \%(41.3-65.1 \%)$ in treatment-naive patients at Year 13, 51.2\% (30.9-75.1\%) in patients previously treated with another DMT at Year 13, and $33.7 \%(25.0-44.4 \%)$ in patients recently treated with another DMT at Year 12; however, the number of patients analyzed at the end of the trial period was low (Fig. 3). At Year 5, the maximum time point at which each treatment subgroup had at least 10 patients, the percentage of patients with 12-week CDW was $33.9 \%$ (30.1-37.9\%) in treatment-naive patients, $36.2 \%(26.9-47.4 \%)$ in previously treated patients, and $33.7 \%(25.0-44.4 \%)$ in recently treated patients (Fig. 3).

EDSS scores were stable across all treatment subgroups over the core and extension period. At the start of teriflunomide $14 \mathrm{mg}$ treatment, mean $(95 \%$ CI) EDSS scores were $2.58(2.50-2.67)$ in treatmentnaive patients $(n=1020), 2.74(2.52-2.96)$ in previously treated patients $(n=163)$, and $2.48(2.26-$ $2.69)$ in recently treated patients $(n=158)$. At Year 8 , the maximum time point at which each subgroup had at least 10 patients, mean (95\% CI) EDSS scores were $2.91(2.65-3.17)$ in treatment-naive patients $(n=150), 2.58(1.84-3.32)$ in patients previously treated with another DMT $(n=24)$, and 3.64 $(2.20$ 5.07) in patients recently treated with another DMT $(n=11)$.

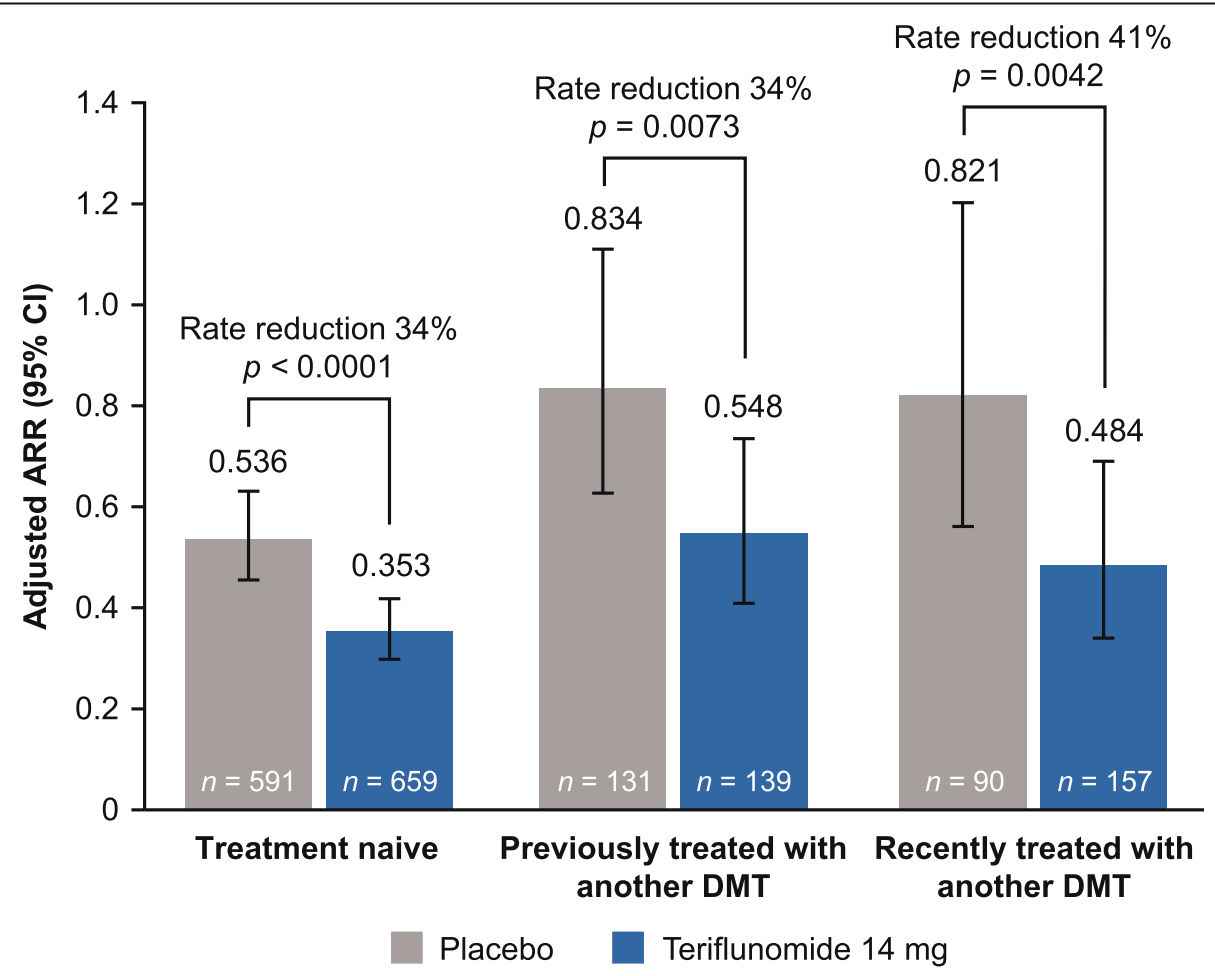

Fig. 1 Adjusted ARR with teriflunomide $14 \mathrm{mg}$ or placebo, stratified by prior treatment history (core period) in the modified intent-to-treat population. The core period for the recently-treated-with-another-DMT group included patients who received IFNB-1a in the core TENERE study who entered the extension and were treated with teriflunomide $14 \mathrm{mg}$; their first 108 weeks on teriflunomide in the extension study were included. The modified intent-to-treat population included patients who received one or more study doses and were analyzed according to the treatment group to which they were randomized. ARR annualized relapse rate, Cl confidence interval, DMT disease-modifying therapy, IFNB interferon beta 


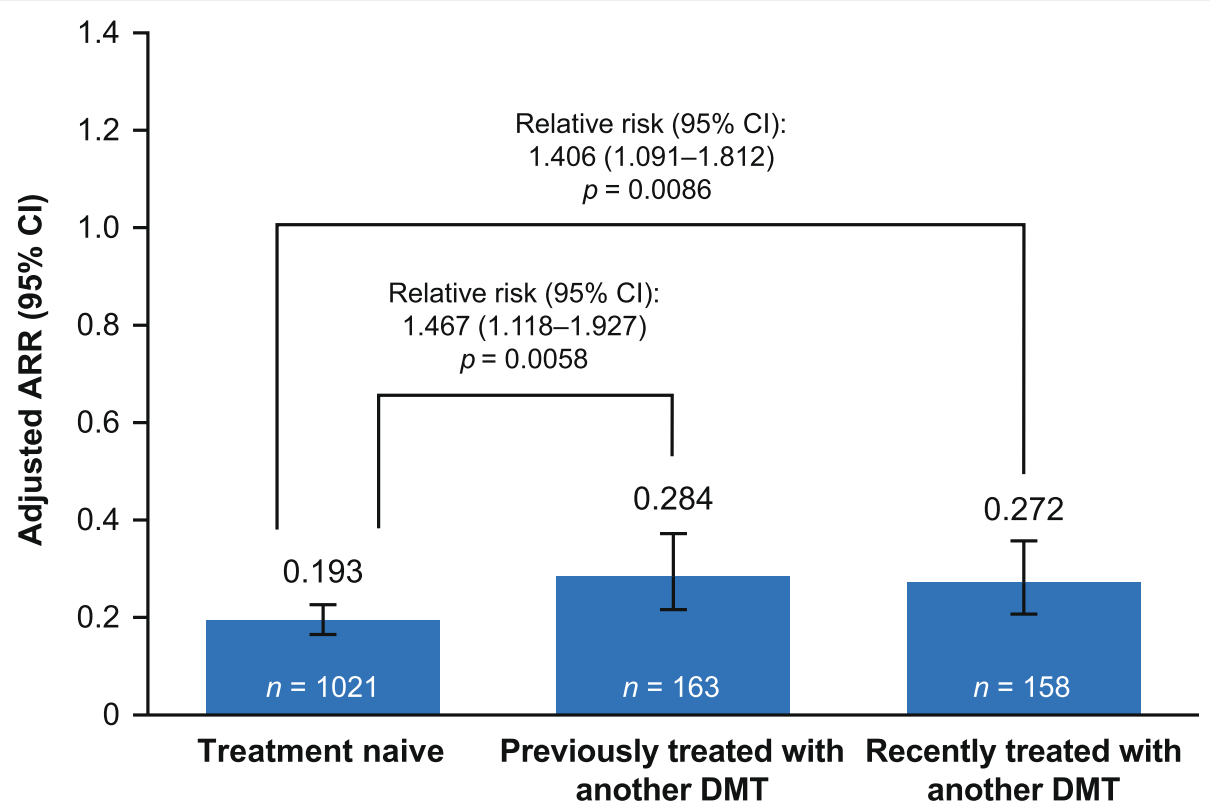

Fig. 2 Overall adjusted ARR in patients treated with teriflunomide $14 \mathrm{mg}$ (core and extension period). ARR annualized relapse rate, $\mathrm{Cl}$ confidence interval, DMT disease-modifying therapy

\section{Safety}

In the core and extension periods, the percentages of patients with AEs and serious AEs were comparable across subgroups $(90.2-96.3 \%$ and $19.3-24.5 \%$, respectively; Table 4). The occurrence of AEs leading to permanent treatment discontinuation was slightly lower in the treatment-naive subgroup (15.2\%; Table 4).
For the treatment-naive, previously treated, and recently treated subgroups, the incidence rates (per 1000 person-years) of any $\mathrm{AE}$ in the core period were 584, 610 , and 456, respectively. By Year 4, respective incidence rates were 327,386 , and 351 . In the core and extension period, the $\mathrm{AE}$ incidence rates were 240,268 , and 298.

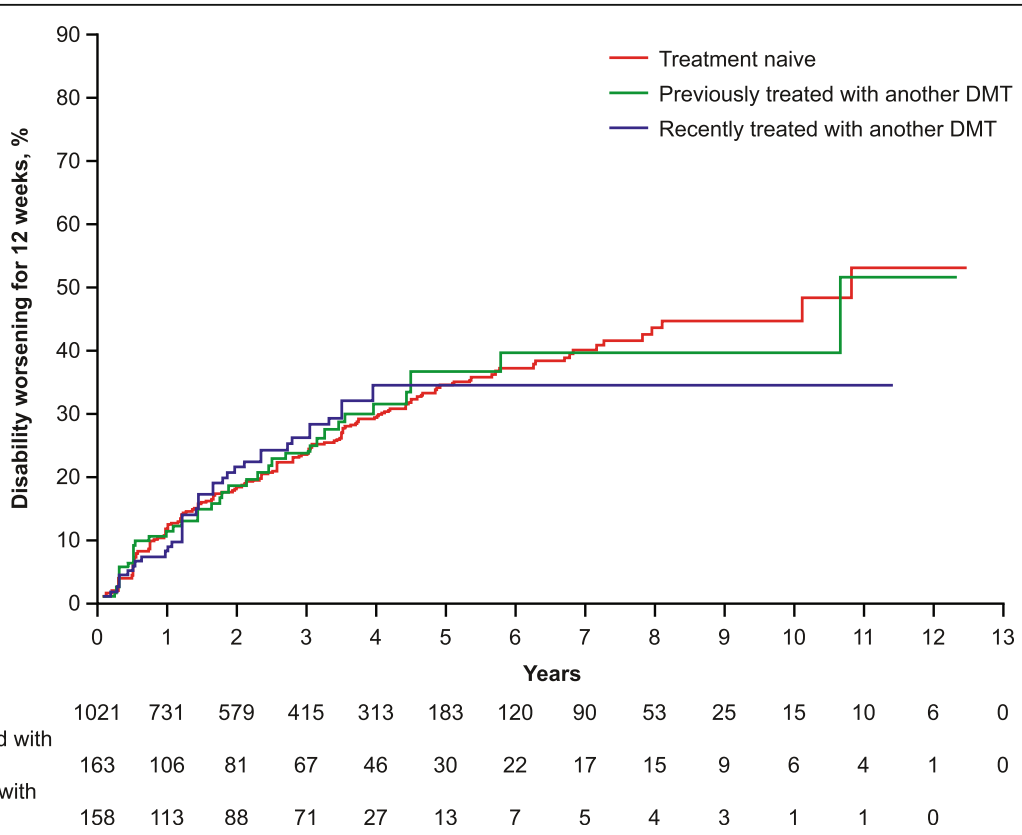

Fig. 3 Percentage of teriflunomide $14 \mathrm{mg}$-treated patients with 12-week CDW (core and extension period). CDW confirmed disability worsening, DMT disease-modifying therapy 
Table 4 Occurrence of AEs with teriflunomide $14 \mathrm{mg}^{\mathrm{a}}$ (core and extension period)

\begin{tabular}{|c|c|c|c|c|}
\hline & Treatment naive $(n=1018)$ & $\begin{array}{l}\text { Previously treated } \\
\text { with another DMT }(n=163)\end{array}$ & $\begin{array}{l}\text { Recently treated } \\
\text { with another DMT }(n=158)\end{array}$ & Overall population $(N=1696)^{\mathrm{b}}$ \\
\hline $\begin{array}{l}\text { Patients with any } \\
\mathrm{AE}, n(\%)\end{array}$ & $918(90.2)$ & $157(96.3)$ & $145(91.8)$ & $1503(88.6)$ \\
\hline $\begin{array}{l}\text { Patients with any } \\
\text { SAE, } n(\%)\end{array}$ & $196(19.3)$ & $40(24.5)$ & $34(21.5)$ & $312(18.4)$ \\
\hline $\begin{array}{l}\text { Patients with any AE } \\
\text { leading to death, } n \\
\text { (\%) }\end{array}$ & $7(0.7)$ & 0 & 0 & $10(0.6)$ \\
\hline $\begin{array}{l}\text { Patients with any AE } \\
\text { leading to } \\
\text { permanent } \\
\text { treatment } \\
\text { discontinuation, } n \\
(\%)\end{array}$ & $155(15.2)$ & $33(20.2)$ & $31(19.6)$ & $244(14.4)$ \\
\hline \multicolumn{5}{|c|}{ AEs with incidence $>10 \%$ in any prior DMT subgroup, $n(\%)$} \\
\hline Nasopharyngitis & $249(24.5)$ & $47(28.8)$ & $36(22.8)$ & $391(23.1)$ \\
\hline ALT increase & $185(18.2)$ & $25(15.3)$ & $18(11.4)$ & $246(14.5)$ \\
\hline Headache & $185(18.2)$ & $32(19.6)$ & $40(25.3)$ & $296(17.5)$ \\
\hline Diarrhea & $178(17.5)$ & $41(25.2)$ & $35(22.2)$ & $284(16.7)$ \\
\hline $\begin{array}{l}\text { Hair thinning } \\
\text { (alopecia) }\end{array}$ & $157(15.4)$ & $28(17.2)$ & $25(15.8)$ & $226(13.3)$ \\
\hline Back pain & $148(14.5)$ & $34(20.9)$ & $21(13.3)$ & 231 (13.6) \\
\hline Fatigue & $136(13.4)$ & $26(16.0)$ & $25(15.8)$ & $203(12.0)$ \\
\hline Influenza & $133(13.1)$ & $26(16.0)$ & $17(10.8)$ & $200(11.8)$ \\
\hline Nausea & 121 (11.9) & $26(16.0)$ & $21(13.3)$ & $184(10.8)$ \\
\hline Pain in extremity & $121(11.9)$ & $24(14.7)$ & $14(8.9)$ & $181(10.7)$ \\
\hline $\begin{array}{l}\text { Upper respiratory } \\
\text { tract infection }\end{array}$ & $121(11.9)$ & $31(19.0)$ & $23(14.6)$ & $202(11.9)$ \\
\hline $\begin{array}{l}\text { Urinary tract } \\
\text { infection }\end{array}$ & $113(11.1)$ & $29(17.8)$ & 21 (13.3) & 197 (11.6) \\
\hline Paresthesia & $102(10.0)$ & $24(14.7)$ & $15(9.5)$ & $157(9.3)$ \\
\hline Hypoesthesia & $99(9.7)$ & $22(13.5)$ & $14(8.9)$ & $148(8.7)$ \\
\hline Hypertension & $94(9.2)$ & $18(11.0)$ & $21(13.3)$ & $157(9.3)$ \\
\hline Arthralgia & $93(9.1)$ & $22(13.5)$ & $14(8.9)$ & 147 (8.7) \\
\hline Bronchitis & $78(7.7)$ & $18(11.0)$ & $15(9.5)$ & $126(7.4)$ \\
\hline Sinusitis & $68(6.7)$ & $24(14.7)$ & $16(10.1)$ & $126(7.4)$ \\
\hline Fall & $67(6.6)$ & $20(12.3)$ & 17 (10.8) & $120(7.1)$ \\
\hline $\begin{array}{l}\text { Abdominal pain, } \\
\text { upper }\end{array}$ & $60(5.9)$ & $10(6.1)$ & 19 (12.0) & $98(5.8)$ \\
\hline Insomnia & $56(5.5)$ & $20(12.3)$ & $12(7.6)$ & $94(5.5)$ \\
\hline Gastroenteritis & $50(4.9)$ & $18(11.0)$ & $13(8.2)$ & $94(5.5)$ \\
\hline
\end{tabular}

${ }^{\mathrm{a}}$ Data are reported for AEs occurring after patients started teriflunomide $14 \mathrm{mg}$; ${ }^{\mathrm{b}}$ Includes an additional cohort of 357 patients from the TOWER and TENERE studies who switched from teriflunomide $7 \mathrm{mg}$ to $14 \mathrm{mg}$ in the extension period; $A E$ adverse event, $A L T$ alanine aminotransferase, DMT disease-modifying therapy, $S A E$ serious adverse event

There were no new or unexpected safety findings with teriflunomide $14 \mathrm{mg}$ in any of the subgroups of prior treatment status. The most frequently reported AEs included nasopharyngitis, alanine aminotransferase increase, headache, diarrhea, and hair thinning (alopecia). Seven deaths were reported, all in the treatment-naive group, and were due to pulmonary tuberculosis and suicide (both reported as potentially related to teriflunomide), and tachycardia, acute cardiac failure, gastrointestinal hemorrhage, suicide, and septicemia (none deemed to be related to teriflunomide). 


\section{Discussion}

In this post hoc analysis, ARRs were significantly lower with teriflunomide $14 \mathrm{mg}$ versus placebo in the core studies and remained low in the core and extension periods in patients who were treatment naive, previously treated with another DMT, or recently treated with another DMT. Although prior treatment status did not affect teriflunomide treatment effect versus placebo, treatment-experienced patients overall had higher ARRs than those who were treatment naive. This may be explained by the inclusion criterion for active disease at core study baseline, selecting for patients with suboptimal DMT response in the treatment-experienced subgroups. However, prior treatment status did not affect disability outcomes after teriflunomide initiation. At Year 5, 12-week CDW was similar across all subgroups, and EDSS scores remained stable through Year 8. These results suggest that regardless of treatment history, teriflunomide $14 \mathrm{mg}$ is efficacious in the short- and longterms.

Long-term efficacy of teriflunomide may be related to its mechanism of action. Teriflunomide is an inhibitor of de novo pyrimidine biosynthesis, through a mechanism that also decreases oxidative phosphorylation. High-affinity $\mathrm{T}$ cells have greater dependence than lower-affinity $\mathrm{T}$ cells on oxidative phosphorylation to supply energy; therefore, teriflunomide may have a selective antiproliferative effect on high-affinity autoimmune T-cell clones. This effect may both shape the T-cell receptor repertoire (by preventing expansion of autoimmune clones) and decrease autoimmune $\mathrm{T}$-cell levels relative to inducible regulatory $\mathrm{T}$ cells [11].

The safety data observed in this pooled post hoc analysis were consistent with previous findings; no new or unexpected safety findings were observed. The incidence rate of AEs in the core plus extension period was higher when analyzed through Year 4 compared with through the end of the trial period, suggesting that most AEs occur relatively early after teriflunomide initiation and decline as treatment continues. Regarding the deaths in the study, signal assessments, safety governance, and medical evaluations have not established a causative role of teriflunomide in the fatal outcomes, but rather a number of other causes were plausible.

Several limitations are associated with this study. As in all extension studies, there was a progressive loss of evaluable patients over the duration of the followup periods across all subgroups. Thus efficacy outcomes could be biased by the selective loss of poor responders, although patient attrition over time was also due to variable study durations and the timing of teriflunomide availability in each country. The number of patients also varied within each subgroup. Additional magnetic resonance imaging (MRI) data, including T2 hyperintense lesions and brain atrophy, would further clarify the effect of prior treatment status on teriflunomide efficacy.

\section{Conclusions}

Across prior DMT subgroups, treatment with teriflunomide $14 \mathrm{mg}$ produced similar treatment effect on relapses, with stable disability, and no apparent effect on tolerability and safety. These data may help to guide treatment decision making in the clinical setting, particularly in treatment-naive patients or those who do not respond to older first-line therapies.

\section{Supplementary information}

Supplementary information accompanies this paper at https://doi.org/10. 1186/s12883-020-01937-4

Additional file 1: Supplementary Table 1. List of Institutional Review Boards and Independent Ethics Committees that approved the procedures at each participating site for the phase 2 clinical trial (A), and phase 3 TEMSO (B), TOWER (C), and TENERE (D) clinical trials.

\section{Abbreviations}

AE: Adverse event; ARR: Annualized relapse rate; CDW: Confirmed disability worsening; Cl: Confidence interval; DMT: Disease-modifying therapy; EDSS: Expanded Disability Status Scale; GA: Glatiramer acetate;

IFNB: Interferon beta; MRI: Magnetic resonance imaging; MS: Multiple sclerosis; RMS: Relapsing forms of multiple sclerosis

\section{Acknowledgments}

The authors and Sanofi thank the patients for their participation in the studies, as well as the Steering Committees and the investigators in the phase 2 and phase 3 TEMSO, TOWER, and TENERE trials and their extension studies. Critical review of the manuscript was provided by Darren P Baker, PhD, Karyn Liu, PhD, and Jonathan Valenzano, PharmD, of Sanofi. Editorial and medical writing support was provided by Richard J Hogan, PhD, and Valerie P Zediak, PhD, of Eloquent Scientific Solutions.

\section{Authors' contributions}

GC acquired and interpreted data, and critically revised the manuscript. MSF acquired and interpreted data, and critically revised the manuscript. JEM-L acquired and interpreted data, and critically revised the manuscript. PV acquired and interpreted data, and critically revised the manuscript. BJK acquired and interpreted data, and critically revised the manuscript. AP acquired and interpreted data, and critically revised the manuscript. KRE acquired and interpreted data, and critically revised the manuscript. RG acquired and interpreted data, and critically revised the manuscript. HK designed and conceptualized the analysis, interpreted data, and critically revised the manuscript. JC designed and conceptualized the analysis, interpreted data, and critically revised the manuscript. EMP designed and conceptualized the analysis, analyzed the data, interpreted data, and critically revised the manuscript. PKC acquired and interpreted data, and critically revised the manuscript. All authors read and approved the final manuscript.

\section{Funding}

The phase 2 and phase 3 TEMSO, TOWER, and TENERE trials and their extension studies were funded by Sanofi. The sponsor was involved in the study design, collection, analysis, and interpretation of data, as well as verification of the data presented in the manuscript. The authors had unrestricted access to study data, were responsible for all content and editorial decisions, and received no honoraria related to the development of this publication. Medical writing support for the development of this paper was funded by Sanofi. 


\section{Availability of data and materials}

Qualified researchers may request access to patient-level data and related study documents including the clinical study report, study protocol with any amendments, blank case report form, statistical analysis plan, and dataset specifications. Patient-level data will be anonymized and study documents will be redacted to protect the privacy of the trial participants. Further details on Sanofi's data-sharing criteria, eligible studies, and process for requesting access can be found at https://www.clinicalstudydatarequest.com.

\section{Ethics approval and consent to participate}

In the multiple studies comprising this post hoc pooled analysis, the protocols were approved by central and local ethics committees and the review board at each of the multiple sites (see Supplementary Table 1 in supplementary information for details). Patients provided written informed consent before participating in the trials. All studies were carried out in accordance with the International Conference on Harmonisation Guidelines for Good Clinical Practice and the World Medical Association's Declaration of Helsinki and its amendments.

\section{Consent for publication}

Not applicable.

\section{Competing interests}

Giancarlo Comi: Compensation for consulting services and/or speaking activities (Almirall, Biogen, Celgene, Excemed, Forward Pharma, Genzyme, Merck, Novartis, Receptos, Roche, Sanofi, Teva); fees for non-CME services (Almirall, Bayer, Biogen, Excemed, Genzyme, Merck Serono, Novartis, Receptos, Sanofi, SSIF, Teva). Mark S Freedman: Research/educational grant support (Genzyme); honoraria/consulting fees (Actelion [J\&J], Bayer HealthCare, Biogen, Chugai, EMD Canada, Genzyme, Merck, Novartis, Roche, Sanofi, Teva Canada Innovation); member of company advisory boards/board of directors/other similar group (Bayer HealthCare, Biogen, Chugai, Genzyme, Merck Serono, Novartis, Roche, Sanofi, Teva Canada Innovation). José E MecaLallana: Grants or speaking and consultation honoraria (Almirall, Biogen, Celgene, Genzyme, Merck, Novartis, Roche, Teva). Patrick Vermersch: Honoraria, consulting fees (Almirall, Bayer, Biogen, Celgene, Genzyme, GSK, Merck Serono, Novartis, Sanofi, Servier, Teva); research support (Bayer, Biogen, Genzyme, Merck Serono, Sanofi). Byoung Joon Kim: Honoraria, consulting fees (Astellas, Bayer, Celltrion, Corestem, Genuv, Genzyme). Alexander Parajeles: Nothing to disclose. Keith R Edwards: Consulting fees (EMD Serono); research support (Biogen, Genentech, Novartis, Sanofi). Ralf Gold: Consulting fees (Bayer Schering, Biogen, Elan, Genzyme, Roche, Teva); grant/research support (Bayer Schering, Biogen, Genzyme, Teva). Houari Korideck and Elizabeth M Poole: Employees of Sanofi at the time the study was conducted. Jeffrey Chavin: Employee of Sanofi. Patricia K Coyle: Consulting fees (Accordant, Biogen, Genentech/Roche, Genzyme/Sanofi, Novartis, Serono, TG Therapeutics); research support (Actelion, Alkermes, Corrona LLD, Genentech/ Roche, MedDay, NINDS, Novartis).

\section{Author details}

${ }^{1}$ Ospedale San Raffaele, Via Olgettina 58, 20132 Milan, Italy. ${ }^{2}$ University of Ottawa and The Ottawa Hospital Research Institute, 501 Smyth Rd, Box, Ottawa, ON 601, Canada. ${ }^{3}$ National Multiple Sclerosis Reference Center (CSUR), Hospital Virgen de la Arrixaca (IMIB-Arrixaca), Ctra, Madrid-Cartagena, s/n, 30120 Murcia, Spain. ${ }^{4}$ Cátedra de Neuroinmunología Clínica y Esclerosis Múltiple, UCAM Universidad Católica San Antonio de Murcia, Campus de los Jerónimos, 30107 Murcia, Guadalupe, Spain. ${ }^{5}$ Univ. Lille, INSERM UMR-S1172 Lille Neuroscience et Cognition, CHU Lille, FHU Imminent, Lille, France. ${ }^{6}$ Department of Neurology, Samsung Medical Center, Sungkyunkwan University School of Medicine, 81 Ilwon-ro, Gangnam-gu, Seoul, South Korea. ${ }^{7}$ San Juan de Dios Hospital, Paseo Colón, Merced, San José, Costa Rica. ${ }^{8}$ Multiple Sclerosis Center of Northeastern New York, 1182 Troy-Schenectady Rd, Ste 203, Latham, NY 12110, USA. 'St Josef Hospital, Ruhr University Bochum, 5092414 Gudrunstrasse 56, D-44791 Bochum, Germany. ${ }^{10}$ Sanofi, 500 Kendall Street, 6th Floor, Cambridge, MA 02142, USA. " 1 Present address: Dana-Farber Cancer Institute, Boston, MA, USA. ${ }^{12}$ Present address: Bluebirdbio, Cambridge, MA, USA. ${ }^{13}$ Department of Neurology, Stony Brook University, HSC T12-020, Stony Brook, NY 11794-8121, USA.
Received: 8 April 2020 Accepted: 23 September 2020

Published online: 06 October 2020

\section{References}

1. Biotti $D$, Ciron J. First-line therapy in relapsing remitting multiple sclerosis. Rev Neurol (Paris). 2018;174:419-28.

2. De Angelis F, John NA, Brownlee WJ. Disease-modifying therapies for multiple sclerosis. BMJ. 2018;363:k4674.

3. Mikol DD, Barkhof F, Chang P, Coyle PK, Jeffery DR, Schwid SR, et al. Comparison of subcutaneous interferon beta-1a with glatiramer acetate in patients with relapsing multiple sclerosis (the REbif vs Glatiramer acetate in relapsing MS disease [REGARD] study): a multicentre, randomised, parallel, open-label trial. Lancet Neurol. 2008;7:903-14.

4. Genzyme Corporation. AUBAGIO (teriflunomide) prescribing information. (2019) http://products.sanofi.us/Aubagio/Aubagio.pdf. Accessed 29 Oct 2019.

5. Sanofi-Aventis Groupe. AUBAGIO (teriflunomide) summary of product characteristics. (2020) https://www.ema.europa.eu/en/documents/productinformation/aubagio-epar-product-information_en.pdf. Accessed 19 Aug 2020.

6. O'Connor PW, Li D, Freedman MS, Bar-Or A, Rice GP, Confavreux C, et al. A phase II study of the safety and efficacy of teriflunomide in multiple sclerosis with relapses. Neurology. 2006;66:894-900.

7. O'Connor P, Wolinsky JS, Confavreux C, Comi G, Kappos L, Olsson TP, et al. Randomized trial of oral teriflunomide for relapsing multiple sclerosis. $\mathrm{N}$ Engl J Med. 2011:365:1293-303.

8. Confavreux C, O'Connor P, Comi G, Freedman MS, Miller AE, Olsson TP, et al. Oral teriflunomide for patients with relapsing multiple sclerosis (TOWER): a randomised, double-blind, placebo-controlled, phase 3 trial. Lancet Neurol. 2014;13:247-56.

9. Vermersch P, Czlonkowska A, Grimaldi LM, Confavreux C, Comi G, Kappos L, et al. Teriflunomide versus subcutaneous interferon beta-la in patients with relapsing multiple sclerosis: a randomised, controlled phase 3 trial. Mult Scler. 2014;20:705-16.

10. Freedman MS, Wolinsky JS, Comi G, Kappos L, Olsson TP, Miller AE, et al. The efficacy of teriflunomide in patients who received prior diseasemodifying treatments: subgroup analyses of the teriflunomide phase 3 TEMSO and TOWER studies. Mult Scler. 2018;24:535-9.

11. Klotz L, Eschborn M, Lindner M, Liebmann M, Herold M, Janoschka C, et al. Teriflunomide treatment for multiple sclerosis modulates $\mathrm{T}$ cell mitochondrial respiration with affinity-dependent effects. Sci Transl Med. 2019;11:eaao5563.

\section{Publisher's Note}

Springer Nature remains neutral with regard to jurisdictional claims in published maps and institutional affiliations.

Ready to submit your research? Choose BMC and benefit from:

- fast, convenient online submission

- thorough peer review by experienced researchers in your field

- rapid publication on acceptance

- support for research data, including large and complex data types

- gold Open Access which fosters wider collaboration and increased citations

- maximum visibility for your research: over $100 \mathrm{M}$ website views per year

At BMC, research is always in progress.

Learn more biomedcentral.com/submissions 